\title{
A systematic review and meta-analysis of Job stress among Iranian nurses
}

Parvaneh Isfahani

Zabol University of Medical Sciences

Marzieh Arefy

Zabol University of Medical Sciences

Saeed Peyravi

Maragheh University of Medical Sciences

Rasoul Corani Bahador

Tabriz University of Medical Sciences

Mahnaz Afshari ( $\nabla$ afshari.m@tak.iums.ac.ir)

https://orcid.org/0000-0003-1349-2588

Research article

Keywords: Nurse,

Posted Date: June 23rd, 2020

DOl: https://doi.org/10.21203/rs.2.24414/v2

License: (a) This work is licensed under a Creative Commons Attribution 4.0 International License.

Read Full License 
The authors have withdrawn this preprint from Research Square 